This PDF is a selection from a published volume from the National Bureau of Economic Research

Volume Title: Health Care Issues in the United States and Japan

Volume Author/Editor: David A. Wise and Naohiro Yashiro, editors

Volume Publisher: University of Chicago Press

Volume ISBN: 0-262-90292-7

Volume URL: http://www.nber.org/books/wise06-1

Conference Date: May 1-3, 2003

Publication Date: September 2006

Title: Does Caregiving Affect Work? Evidence Based on Prior Labor Force Experience

Author: Kathleen M. McGarry

URL: http://www.nber.org/chapters/c7366 


\title{
Does Caregiving Affect Work? Evidence Based on Prior Labor Force Experience
}

\author{
Kathleen McGarry
}

\subsection{Introduction}

The aging of a population presents numerous problems with which a country must grapple. Public attention in the United States and around the developed world has focused on the financial solvency of pension programs, the demands placed on the formal health care sector, and the expected increases in aggregate health care costs. However, of perhaps more direct concern to individuals and families, is the prospect of caring for a frail elderly family member, particularly an elderly parent. The United States General Accounting Office estimates that by 2040 there could be as many as 12 million disabled elderly (Walker 2002). Based on current caregiving patterns, the vast majority of these needy individuals will receive care exclusively through informal networks of family and friends, most typically a spouse or child (Department of Health and Human Services 1998). Intuitively one would expect this caregiving to affect the labor market behavior of the provider; caregivers may reduce hours or exit employment entirely in response to the needs of an elderly family member. The loss of trained workers will likely negatively affect the productivity of the economy, a drain made potentially more serious in light of the aging of the population and the declining ratio of workers to retirees.

On an individual level, reductions in labor market activity would be expected to affect later financial well-being. Not only would there be the obvious decline in earnings and thus an expected decline in retirement savings,

Kathleen McGarry is a professor of economics at the University of California, Los Angeles, and a research associate of the National Bureau of Economic Research.

I thank Hui Cao for bibliographic assistance and gratefully acknowledge financial support from the National Institute on Aging. 
but future pension benefits may be adversely affected as well. These adverse effects may be especially severe for women as they comprise the majority of caregivers and, perhaps for this reason, the majority of poor elderly.

The concern among lawmakers over the potential impacts of caregiving on employment is evidenced by such policies as the Family Medical Leave Act of 1993 and the Older Americans Act Amendments of 2000. ${ }^{1}$ However, despite the expected labor force consequences, the relevant academic literature has not yet provided a definitive examination of the relationship between work and caregiving. Not only is the magnitude of the effect uncertain, but research has differed even on the existence of a negative effect. Several papers have reported strong negative effects of caregiving on work, while others have found little relationship.

Empirical analysis of the work-caregiving trade-off is not straightforward. Market work and caregiving are certainly competing uses of one's time, suggesting a negative relationship between the two. However, it is not clear whether those who provide care do so because they are working fewer hours or if they work fewer hours because of their caregiving chores. In assessing the labor market effects, and the potential policy response, causality is important.

This paper takes advantage of a longitudinal panel of observations on employment and caregiving to begin to address this issue. I examine labor market behavior prior to caregiving and note how it differs for those who subsequently provide care and those who do not. I look both at short-term effects through changes in behavior over a two-year period and at more extended effects over a period of six years. My measures of labor market attachment include employment status, hours worked, and expected retirement. I find surprisingly little relationship between previous employment and later caregiving.

The outline of the paper is as follows: section 9.2 provides a description of the long-term care market, including a discussion of the type of insurance coverage available. Section 9.3 sketches the type of model used to examine the labor/leisure/caregiving decisions and highlights some results from the previous literature. In section 9.4, I discuss the data to be used, and in section 9.5, I present the empirical analysis. A final section concludes and offers direction for future research.

\subsection{Background}

In the United States, nearly all elderly are eligible for comprehensive medical insurance through the Medicare program. Although Medicare

1. The Family Medical Leave Act required that employers with fifty or more employees provide employees with twelve weeks of unpaid leave to care for a new child or a family member with a health condition. The Older Americans Act Amendments of 2000 amended the original 1965 Older Americans Act and, among other provisions, established the National Family Support Program. 
provides generous benefits, there are important gaps in coverage. ${ }^{2}$ In particular, Medicare does not cover very long hospital stays or prescription drugs. Most important for this analysis, Medicare also excludes much nursing home care and home health care providing coverage in only a restricted set of circumstances.

Care in nursing homes or, more properly, skilled nursing facilities (SNFs), is covered by Medicare to the extent that it is medically skilled care that is needed to "manage, observe, and evaluate care" and not simply assistance with activities of daily living such as dressing, bathing, eating, or what is termed custodial care. ${ }^{3}$ Furthermore, to be covered by Medicare, this medical need must come within thirty days of a hospital stay that lasted at least three days (or a previous stay at a SNF that was linked to a hospital stay) and must be prescribed and supervised by a doctor or skilled staff. The duration of this care is limited. Medicare covers all costs for the first 20 days, a portion of the cost of days 21 to 100 , but nothing beyond 100 days. $^{4}$

There are similar restrictions on the coverage of home health care. Home health care is covered only if the care is prescribed by a doctor and requires skilled nursing care on an intermittent, rather than full-time, basis. ${ }^{5}$ Further, in order to be eligible for benefits the insured individual must also be homebound. If these conditions are met, Medicare will pay for a skilled nurse or home health aid to visit the home. ${ }^{6}$ The structure of care is then carefully monitored by a doctor who must review the plan of care every sixty days. This requirement assures that the care continues to have the medically needed component.

An important limitation with respect to home care coverage is that Medicare does not pay for help with basic personal needs like dressing, bathing, and toileting, unless the patient also needs medical care. This omission thus leaves a large number of elderly who are unable to live independently, but whose long-term care needs are not covered by Medicare.

For the poor elderly, assistance is available through the Medicaid program. Medicaid is a public health insurance program that benefits those elderly who have little in the way of income or assets.? It is administered on a state level with some financing from the federal government, and thus the specifics of coverage can vary across states. All states do provide nursing

2. See McGarry (2002) for a discussion of the development of the Medicare program and its current coverage.

3. See CMS (n.d.a) for an easy to follow discussion of benefits.

4. The copayment is approximately $\$ 100$ per day. This is covered under some Medigap plans. (Medigap plans are privately purchased health insurance plans that fill some of the gaps in the Medicare program.)

5. Intermitted means that the care required is less than eight hours per day and twenty-eight or fewer hours per week.

6. It will also pay for physical therapy, speech pathology, occupational therapy, medical social services, and medical supplies and equipment (CMS n.d.b).

7. Medicaid also covers other ask risk groups, in particular, pregnant women and children. 
home coverage and some amount of home health care coverage as well, but the generosity of home health services varies.

Those elderly not eligible for Medicaid and concerned about the potential for future long-term care expenditures may purchase private long-term care insurance that covers home health care or nursing home stays. However, these policies have not proved popular, and only 10 percent or so of the elderly are currently covered by this type of insurance (Finkelstein and McGarry Forthcoming). Numerous explanations have been offered for the relatively small size of the long-term care insurance market, with many of the explanations, and the policy prescriptions, focusing on the cost of this insurance. Costs may be high because of informational asymmetries resulting in problems such as moral hazard or adverse selection or simply because the cost of nursing home care is high and increasing rapidly. Longterm care policies may also be unpopular because many provide only limited coverage with caps on daily or lifetime benefits and little inflation protection. $^{8}$

With limited insurance protection, the elderly requiring long-term care face substantial out-of-pocket costs. A Metropolitan Life Insurance Company survey (2002) estimated that the average cost of a year of care in a nursing home in 1997 was $\$ 61,000$ for a private room and $\$ 52,000$ for a semiprivate room. Even home care is expensive, averaging $\$ 37$ per hour for a licensed practical nurse.

Given the high cost of formal care and the lack of insurance coverage, many elderly rely on unpaid, informal care. Although difficult to quantify, the economic value of this care is likely to be substantial. Arno, Levine, and Memmott (1999) provide an estimate of the approximate value of this care by imputing an average wage per hour and multiplying by an estimate of hours of informal care. They use a single wage for all caregiving but experiment with three different values of this wage. Their preferred estimates are based on a wage rate of $\$ 8.18$ per hour. At this price, the value of informal caregiving in 1997 totaled $\$ 196$ billion. At a wage rate of $\$ 11.20$ per hour - their estimate of the average rate for home health aids-the total value was $\$ 288$ billion. These totals dwarf the total expenses in the formal sector. As Arno, Levine, and Memmott (1999) report, total spending for nursing home care in the same year was $\$ 83$ billion, and spending on formal home health care was just $\$ 32$ billion. Informal care is large in economic terms even relative to health expenditures as a whole. Total medical spending in 1997 was $\$ 1,092$ billion, just four or five times larger than the imputed value of informat care. The monetary importance of informal care suggests that it could well have important secondary economic effects.

8. Brown and Finkelstein (2003) and Finkelstein and McGarry (Forthcoming) provide more detailed analyses of these issues. 


\subsection{Theoretical Framework}

The theoretical framework for analyzing the decision to provide longterm care grows out of the standard labor supply literature. A potential caregiver maximizes a standard utility function by comparing the marginal value of providing an hour of care with the value of an hour spent working or enjoying leisure. Consider an altruistic child who cares about his own consumption of market goods, $C_{c}$, his consumption of leisure, $L_{c}$, and the well-being of his parent, $U_{p}$. The parent's utility in turn is positively related to his or her own consumption, $C_{p}$ and his or her health status, $H_{p}$, Health status is enhanced through the provision of home health care, $\mathrm{HC}$; all else constant, the more needy the parent, the more valuable an hour of care. Providing care is costly to the child, however, in that it requires time and thus enters into the child's budget constraint with a price equal to the opportunity cost of the child's time. The child has a finite number of hours, $T$, which he or she can allocate to employment (income), leisure, or caregiving. Thus, time spent helping a parent comes at the expense of reduced consumption of goods or hours of leisure.

Formally, the utility maximization problem can be written as

$$
\begin{gathered}
\max U_{c}=U\left[C_{c}, L_{c}, U_{p}\left(C_{p}, H_{p}\right)\right] \\
\text { subject to: } w T=w L_{c}+p C_{c}+w \mathrm{HC},
\end{gathered}
$$

where $w$ is the child's wage rate (i.e., the opportunity cost of his or her time), $T$ is the total time available, and $p$ is the price of the consumption good. With the standard assumptions about utility functions, one would expect caregiving to be negatively related to the wage so that caregivers ought to have a lower (potential) wage rate $(w)$ than noncaregivers. ${ }^{9}$ This prediction is consistent with the greater likelihood of providing care observed for women relative to men and their relatively lower market wages. ${ }^{10}$

Typically in this literature authors estimate a reduced form specification. Some studies have analyzed the decision to provide care with labor market status as an explanatory variable, while others have examined the reverselabor force participation, or hours worked, as a function of caregiving. The simultaneous nature of the decision process makes it difficult to infer causality from these results.

Furthermore, the empirical relevance of even the apparently straightforward relationship between work and caregiving has been called into question. A number of early studies found a strong negative relationship

9. If one assumes that professional services are a substitute for informal caregiving, then a utility maximizing child could choose to work more hours and provide the parent with the financial resources to purchase care for the elderly parent. I do not address this potential substitution in this chapter.

10. In light of this prediction, the strengthening of the attachment of women may signal a change in future patterns of caregiving. 
between the two tasks (e.g., Dwyer and Coward 1991; Brody and Schoonover 1986; Boaz and Muller 1992; Stone, Cafferata, and Sangl 1987). However, several more recent papers have not found the expected negative effects (Ettner 1996; Stern 1995; Wolf and Soldo 1994). Both sets of results are primarily cross-sectional in nature and thus have a difficult time in assessing the counterfactual-what would work to absent the necessity of caregiving?" ${ }^{11}$ Here I draw on longitudinal data to examine labor market behavior prior to the caregiving decision.

\subsection{Data}

The data for this study are drawn from the Health and Retirement Study (HRS). When appropriately weighted, the HRS is representative of the noninstitutional U.S. population born between 1931 and 1941 and their spouses or partners. ${ }^{12}$ The HRS is a panel survey with the first round interviews taking place in 1992. At that time, respondents were approximately fifty-one to sixty-one years old or were married to individuals in that age range. Follow-up interviews took place every other year. The most recently available data are for 2000 , and I draw on all waves of data (1992, 1994, 1996, 1998, 2000) for this project. ${ }^{13}$

The HRS is uniquely suited for a study of this type. It is individuals in this age range who are most likely to have parents needing assistance with personal care. The Commonwealth Fund (1999) reports that 13 percent of women age forty-five to sixty-four provided care in 1998 compared to 10 percent of women thirty to forty-four and 7 percent of women age sixtyfive or older. Furthermore, whereas many previous studies have been limited to families in which some care was being provided, the HRS contains information on parents and parents-in-law of all respondents, regardless of whether the parent needs or is receiving care, as well as information on each of the respondent's siblings. Thus, I am able to examine behavior in both families that do and those that do not provide some care as well as the effect of family structure on the provision of care. In addition, the HRS is a panel survey. This aspect of the data allows me to examine changes in

11. Stern (1995) is an exception. He uses lagged employment status and distance to a parent as instrumental variables in the child's decision to provide care.

12. Individuals in heavily Black and Hispanic areas were oversampled by the survey. In the tables reported in the following, sample means are weighted to account for the oversampling. Frequencies and regressions are not weighted. When weighting observations, I use the household-level weight rather than the respondent-level weight. Individuals who are outside of the target age range (but who are married to an age eligible respondent) have an individual weight of zero. Rather than lose these observations from the analysis, I assign all respondents the (nonzero) household weight. This procedure is based on discussion with the HRS staff at the University of Michigan.

13. More information on the HRS can be obtained from http://hrsonline.isr.umich.edu/ and in Juster and Suzman (1995). 
caregiving over time and, importantly, to focus on labor market behavior several years prior to the point at which I measure care.

My measure of caregiving is the response to the following question:

"Have you (or your [husband/partner]) spent 100 or more hours in the past twelve months helping (your parent $[\mathrm{s}] /$ stepparents, your husband's/ partner's parent[s]/stepparents) with basic personal needs like dressing, eating, and bathing?"

The survey then asks who was helped and how many hours of care the respondent and, separately her spouse provided. ${ }^{14}$ One should note that the question asks specifically about help with personal care needs rather than help in general. In the 1992 interview, this was the only question asked about time help. Later interviews also asked about help with household chores. Because I am specifically focusing on the provision of home health care, I restrict my analysis to responses to the questions about help with personal care even in waves in which more information is available.

The questions on the provision of care changed over the interview waves in other ways as well. In the 1994 interview the question was changed to ask about 50 or more hours of care (rather than 100) although the reference period again asked about care over the past twelve months. In 1996, the cutoff point was returned to 100 hours, but the period was changed to the length of time elapsed since the previous interview (or two years for new respondents). Subsequent waves have retained this 100 hours/two-year format. I do not adjust the data for these differences.

The question about labor force participation is more straightforward. I use the response to the question "Are you doing any work for pay?" The hours-worked variable is the sum of usual hours worked on a main job and a second job (if one exists). Earnings are for the previous calendar year (i.e., the 1992 survey collects information on 1991 earnings) and include earnings from a second job, and any bonuses or overtime payments, as well as earnings on the main job.

I place several restrictions on the sample. First, because women are consistently found to be more likely to provide care than men (Coward and Dwyer 1990; Dwyer and Coward 1991; Wolf, Freedman, and Soldo 1997; McGarry 1998), past studies have typically focused on women. I follow this example and restrict my sample to women. I also restrict my sample to those who have a living parent or parent-in-law in at least one wave of the survey. In the latter portion of the analysis, I draw primarily on data from a single wave and use information from earlier time periods as controls. In these exercises I rely on 1998 data rather than data from 2000 . The choice

14. These questions are asked only once per HRS household. For married couples, these and other questions on family relationships were typically provided by the female respondent. 
Work and caregiving in 1992

\begin{tabular}{|c|c|c|c|c|c|c|}
\hline \multirow[b]{2}{*}{ Variable } & \multicolumn{2}{|c|}{$\begin{array}{c}\text { All } \\
(N=3,937)^{\mathrm{a}}\end{array}$} & \multicolumn{2}{|c|}{$\begin{array}{l}\text { Providing care } \\
\quad(N=243)\end{array}$} & \multicolumn{2}{|c|}{$\begin{array}{l}\text { Not providing care } \\
\qquad(N=3,691)\end{array}$} \\
\hline & Mean & $\begin{array}{l}\text { Standard } \\
\text { error }\end{array}$ & Mean & $\begin{array}{l}\text { Standard } \\
\text { Error }\end{array}$ & Mean & $\begin{array}{c}\text { Standard } \\
\text { error }\end{array}$ \\
\hline Works for pay & 0.65 & 0.006 & 0.60 & 0.03 & 66 & 0.007 \\
\hline $\begin{array}{l}\text { Hours of work } \\
\text { (positive) }\end{array}$ & 38.4 & 227 & 41.7 & 1.15 & 38.2 & 0.23 \\
\hline Earnings (positive) & 20,673 & 289 & 18,016 & 984 & 20,725 & 304 \\
\hline $\begin{array}{l}\text { Provides care } \\
\quad \text { (if living parent) }\end{array}$ & 0.06 & 0.003 & 1.0 & 0 & 0 & 0 \\
\hline $\begin{array}{l}\text { Hours of care } \\
\quad \text { (unconditional) }\end{array}$ & 34.4 & 4.4 & 592.9 & 67.7 & 0 & 0 \\
\hline
\end{tabular}

aCaregiving status is missing for 175 respondents

of the penultimate year of available data allows me to use lagged values of labor market participation back to 1992, six years prior to the caregiving arrangement I observe, while at the same time avoiding the much larger reduction in sample size that comes from a fall in the number of respondents with living parents when looking out to $2000 .{ }^{15}$ This initial sample consists of 3,937 women in 1992 .

\subsection{Results}

\subsubsection{Cross-Sectional Examination of Caregiving}

The focus of this analysis is on work and caregiving. In simple correlations, many past studies have observed less labor market activity (i.e., lower employment rates or fewer hours worked) among caregivers. Table 9.1 reports the mean probability of working, mean hours of work and earnings (both conditional on having nonzero values), and mean hours of care in 1992 for my sample of 3,937 respondents with a living parent or parent-inlaw in that year. Sixty-five percent of these women were working for pay. As is typical of past studies, the probability of working differs by caregiving status: 60 percent of caregivers and 66 percent of noncaregivers were employed. Thus, at first glance, caregivers do appear to have a weaker attachment to the labor force. Conditional on working, however, caregivers ac-

15. By the year 2000 , interview respondents are approximately fifty-nine to sixty-nine years old, indicating that their parents would likely be well over eighty. There are thus many fewer respondents with living parents or parents-in-law; the number of female respondents with a living parent or parent-in-law falls from 2,759 in 1998 to 1,633 in 2000. Thus, restricting the sample to those with living parents or parents-in-law in 2000 results in an even more selected group and likely reduces the precision of any estimates. 
tually work more hours than noncaregivers, forty-two versus thirty-eight hours on average, a statistically significant difference. However, despite the greater number of hours, caregivers have significantly lower earnings. This result is consistent with a lower opportunity cost of time among caregivers (i.e., lower wage rate). Thus, while caregivers do not appear to be reducing hours worked (conditional on employment) in order to provide care, their lower earnings is consistent with less intensive investment in the job, perhaps with associated smaller raises or bonuses or less overtime. ${ }^{16}$

\subsubsection{Transitions between Work and Caregiving}

Past studies of caregiving behavior have primarily been limited to this type of point-in-time analysis. However, of perhaps greater interest than simple cross-sectional comparisons is an understanding of causality. Are caregivers less likely to work because they are providing care? Or are they providing care because they have always had a less strong attachment to the labor force than noncaregivers? The latter would be expected if the family were maximizing a joint utility function where the member with the lowest opportunity cost of time would be selected to provide care. By taking advantage of the panel nature of the HRS data set I begin to address this issue. Here I examine transitions into and out of caregiving and observe the employment status of caregivers prior to the actual provision of care.

I begin by simply examining the prevalence of various types of crosswave transitions. Table 9.2 shows the fraction of the sample of transiting between each of four possible work and caregiving states: not working and not providing care, working and not providing care, providing care and not working, providing care and working. The data from each of the five survey years $(1992,1994,1996,1998$, and 2000) are stacked together so that an individual may provide multiple observations. ${ }^{17} \mathrm{I}$ again use the sample of 3,937 women with a living parent or parent-in-law in at least one wave but drop the observation when the woman's last parent or parent-in-law dies. Thus, an individual may not contribute data to the table for all periods 1992 to 2000 even though she responds to the survey in every period. This procedure yields a sample of 11,184 year-to-year observations. ${ }^{18}$

16. An important assumption in this literature, and in the literature on labor supply in general, is that individuals can freely choose the number of hours they work. It should be noted, here and throughout the discussion that follows, that this assumption may not hold. Hurd and McGarry (1993) find that only one-quarter of workers can decrease hours on their current job. Change may therefore be more readily observed in complete departures from the labor force. I will present evidence on both dimensions.

17. Single year-by-year comparisons show similar patterns. I report one such comparison in the following.

18. However, if the individual has more than one living parent or parent-in-law, a particular parent may die between waves and the individual remains in the sample. Some of the transitions to noncaregiving states are likely associated with the death of the parent initially receiving care. 


\begin{tabular}{|c|c|c|c|c|c|}
\hline \multirow[b]{2}{*}{ Time $t$} & \multicolumn{5}{|c|}{ Time $t+1$} \\
\hline & $\begin{array}{c}\text { Not } \\
\text { working/not } \\
\text { caregiving }\end{array}$ & $\begin{array}{c}\text { Working } \\
\text { only }\end{array}$ & $\begin{array}{l}\text { Caregiving } \\
\text { only }\end{array}$ & $\begin{array}{l}\text { Working/ } \\
\text { caregiving }\end{array}$ & Total \\
\hline \multicolumn{6}{|c|}{ Not working, not caregiving } \\
\hline Number & 2,875 & 455 & 320 & 47 & 3,697 \\
\hline Percent of row & 77.0 & 12.5 & 9.2 & 1.4 & 100 \\
\hline \multicolumn{6}{|l|}{ Working only } \\
\hline Number & 842 & 5,100 & 931 & 457 & 6,492 \\
\hline Percent of row & 13.1 & 78.6 & 1.4 & 6.9 & 100 \\
\hline \multicolumn{6}{|l|}{ Caregiving only } \\
\hline Number & 182 & 31 & 181 & 26 & 420 \\
\hline Percent of row & 45.9 & 7.6 & 40.7 & 5.9 & 100 \\
\hline \multicolumn{6}{|c|}{ Working, caregiving } \\
\hline Number & 61 & 284 & 32 & 198 & 575 \\
\hline Percent of row & 11.1 & 50.0 & 5.4 & 33.5 & 100 \\
\hline Total & 3,960 & 5,870 & 626 & 728 & \\
\hline
\end{tabular}

Note: Percents are weighted values; counts are unweighted.

The working and caregiving state in any period $t$ is denoted on the left (vertical) column of table 9.2, and the state in the following interview; time $t+1$, is shown in the top row (horizontal). The majority of observations correspond to working only in wave $t$ (row 2); 6,492 out of 11,184 observations fall into this category. Arguably it is this group who is most at risk for changing employment status in response to caregiving, and I will focus most of the discussion on their behavior. Among those in this category, the vast majority, nearly 80 percent, continue to be working only at time $t+1$, while just 8.3 percent $(1.4+6.9)$ begin providing care.

The second most common initial state is not working and not caregiving, containing 3,697 observations. As with the case of the working only row, the majority ( 77 percent) of this group remain in this same arrangement in the following period. Ex post one would expect those who are not working to have a lower opportunity cost of time and to be more likely to take up caregiving than those who are employed. However, by comparing the first and second set of rows in the table it is apparent that the differences between the two groups in the probability of transitioning to a caregiving state are not large: 10.6 percent $(9.2+1.4)$ of the not working and not caregiving sample begins providing care by time $t+1$, compared to 8.3 percent of the working sample. Furthermore, of the 8.3 percent of working onlys who begin to provide care, only 17 percent (1.4/8.3) discontinue working at the same time. This figure is similar to the 13.1 percent of working onlys who leave the labor force but do not provide care, indicating a potentially weaker than anticipated causal relationship between work and caregiving. 
The two final rows of table 9.2 provide evidence on what happens from one period to the next for those who are already providing care. A surprisingly large fraction of those providing care (either with or without work) transit out of the caregiving arrangement. More than 50 percent of those caregiving only in period $t$ were not caregiving in period $t+1$, and over 60 percent of those who were initially working and caregiving were no longer caregiving in the second period. The transition out of caregiving could arise from an improvement in the health of the needy parent or a switch to an alternative caregiving arrangement (e.g., care being provided by a sibling of the respondent or professional caregiver). However, note that the selection criterion require only that the respondent have at least one living parent or parent-in-law, but there is no requirement that the number of living parents remain constant throughout the observation period. Some of the transitions out of caregiving are therefore likely attributable to the death of the particular parent who was receiving care.

Further evidence of the transitory nature of caregiving is available by examining the average number of years for which care is provided. Although not shown in the table, the average number of surveys for which a respondent reports providing care is below 2 for nearly all cells in the table. The highest value is 2.5 for those caregiving only in both waves. Based on these figures then, caregiving appears to be a relatively temporary state for many women.

Not only were those who were working only relatively unlikely to cease employment in response to the onset of caregiving, but many of those who were caregiving only became employed while maintaining their roles as caregivers. The fraction of caregiving onlys who do start to work, 13.5 percent $(7.6+5.9)$, is lower than the fraction of those not working and not caregiving who become employed, 13.9 percent $(12.5+1.4)$, but the difference is small.

Table 9.3 parallels table 9.2 but each cell reports the average hours worked, average earnings in wave $t$, the average change in hours of work between waves, and average hours of care provided in wave $t+1$. Again I focus first on the second row of the table and examine the behavior of those who were working only at time $t$. Within this category, those who leave the labor force by time $t+1$ are initially working significantly fewer hours than those who remain. This result holds regardless of whether the woman transits to not working and not caregiving or to caregiving only. The two groups average just seventeen hours and fifteen hours per week at time $t$, respectively. In contrast, both those who remain in the working only category and those who take up caregiving along with work report an average of thirty-nine hours of work per week, identical to that worked by those who do not provide care.

Also worth noting are hours of work for those who were initially working and caregiving (bottom set of results). Those who continue to both 


\begin{tabular}{lrrrr}
\hline & \multicolumn{4}{c}{ Time $t+1$} \\
\cline { 2 - 5 } Time $t$ & $\begin{array}{c}\text { Not } \\
\text { working/not } \\
\text { caregiving }\end{array}$ & $\begin{array}{c}\text { Working } \\
\text { only }\end{array}$ & $\begin{array}{c}\text { Caregiving } \\
\text { only }\end{array}$ & $\begin{array}{r}\text { Working } / \\
\text { caregiving }\end{array}$ \\
\hline Not working, not caregiving & & & & \\
Hours worked $t$ & 0.0 & 0.0 & 0.0 & 0.0 \\
Earnings in previous year & 2,304 & 7,788 & 2,546 & 6,077 \\
Change in hours & 0.0 & 24.7 & 0.0 & 21.1 \\
Hours of care $t+1$ & 0.0 & 0.0 & 452 & 240 \\
Working only & & & & \\
Hours worked $t$ & 17.3 & 39.2 & 15.1 & 39.2 \\
Earnings in previous year & 17,446 & 22,743 & 18,928 & 22,294 \\
Change in hours & -34.8 & -5.0 & -31.4 & -4.5 \\
Hours of care $t+1$ & 0.0 & 0.0 & 299 & 263 \\
Caregiving only & & & & \\
Hours worked $t$ & 0.0 & 0.0 & 0.0 & 0.0 \\
Earnings in previous year & 3,075 & 4,206 & 1,272 & 6,480 \\
Change in hours & 0.0 & 17.8 & 0.0 & 10.9 \\
Hours of care $t+1$ & 0.0 & 0.0 & 691 & 450 \\
Working, caregiving & & & & \\
Hours worked $t$ & 17.4 & 39.4 & 9.4 & 44.2 \\
Earnings in previous year & 13,723 & 22,007 & 28,038 & 20,587 \\
Change in hours & -39.5 & -5.4 & -32.7 & -11.3 \\
Hours of care $t+1$ & 0.0 & 0.0 & 238 & 458 \\
\hline
\end{tabular}

work and provide care average forty-four hours per week, while those who transit to working only were averaged thirty-nine hours. Thus, those who remain caregivers were actually working a greater number of hours while caregiving than those who discontinue care.

The comparison of earnings across groups yields similar results to the hours comparison. ${ }^{19}$ There are no apparent differences in time $t$ earnings by time $t+1$ caregiving status for those working only at time $t$. Earnings in the previous year were $\$ 22,743$ for those who remain in the working only category and $\$ 22,294$ for those who become workers and caregivers. As was the case with hours worked, those who leave the labor force, either to provide care or not, have lower average values than those who remain employed. Those who are eventually caregiving only average $\$ 18,928$ per year, and the eventual nonwork and noncaregivers average $\$ 17,446$.

Earnings are also similar for those who were working and caregiving at time $t$ and who remain employed regardless of whether they continue pro-

19. The earnings reported in the table refer to earnings in the year prior to the time $t$ interview because the survey asks about earnings in the previous year. This explains the nonzero earnings among those not working at time $t$. 
viding care. Those in this group who transit to working only and thus cease providing care averaged $\$ 22,007$ per year, and those who remained in the working and caregiving classification averaged $\$ 20,587$. Surprisingly, those who left the labor force and transited to caregiving only had substantially higher period $t$ average earnings of $\$ 28,038$. However, as shown in table 9.2, there are very few women in this cell, just thirty-two, so one ought to be cautious about putting much weight on this finding.

Not only were labor market positions for noncaregivers and eventual caregivers similar prior to the start of caregiving, but also there is little change resulting from the transition. Among those who were working only, the average change in hours worked across the two waves is negative for both those who begin to provide care and those who do not, falling by 5 hours for those who remain working only and 4.5 for those who work and provide care. Those who stop working obviously have much larger declines in hours.

The hours of care lines in the table 9.3 (the fourth row in each set of results) also provide an interesting insight into behavior. In the working only category, those who take up caregiving provide nearly identical hours of care, on average, regardless of whether they continue working. The caregiving only group supplies an average of 299 hours and the working and caregiving group supplies 263. Again it looks as though the relationship between caregiving and work is weak.

However, among those who were caregiving initially, the hours of care provided are much higher. They average 691 hours among those who are caregiving only at both time $t$ and at time $t+1$, and 450 among those who transit from caregiving only to working and caregiving. Those who were working and caregiving average fewer hours; 238 for those who stop work and 458 for those who continue to do both tasks. Again, however, the sample sizes are small.

\subsubsection{Longer Time Horizon}

The lack of a relationship between labor market behavior and caregiving in table 9.2 and table 9.3 may simply be because caregivers have not had sufficient time to adjust their hours of work. To incorporate a longer range view into this framework, I compare behavior in 1992 with that in 1998. The tables are constructed similarly to tables 9.2 and 9.3 but instead of time $t$ and time $t+1$, I use the individual's status in 1992 and 1998. Caregivers in 1998 could have started providing care at any time after the 1992 interview, but they must still be providing care in 1998 to be classified as such. Thus, the category of caregiving in 1998 will include those new to the chore as well as those who began caring for a parent several periods earlier and who are still providing care. Care provided at some point between 1992 and 1998 but not in either of those years is not observed. Tables 9.4 and 9.5 display the cross-year results. 


\begin{tabular}{|c|c|c|c|c|c|}
\hline \multirow[b]{2}{*}{1992 Status } & \multicolumn{5}{|c|}{1998 Status } \\
\hline & $\begin{array}{c}\text { Not } \\
\text { working/not } \\
\text { caregiving }\end{array}$ & $\begin{array}{l}\text { Working } \\
\text { only }\end{array}$ & $\begin{array}{l}\text { Caregiving } \\
\text { only }\end{array}$ & $\begin{array}{l}\text { Working/ } \\
\text { caregiving }\end{array}$ & Total \\
\hline \multicolumn{6}{|c|}{ Not working, not caregiving } \\
\hline Number & 541 & 147 & 76 & 21 & 785 \\
\hline Percent of row & 68.8 & 18.6 & 9.8 & 2.8 & 100 \\
\hline \multicolumn{6}{|l|}{ Working only } \\
\hline Number & 367 & 1,092 & 64 & 134 & 1,657 \\
\hline Percent of row & 22.7 & 65.7 & 3.7 & 7.9 & 100 \\
\hline \multicolumn{6}{|l|}{ Caregiving only } \\
\hline Number & 23 & 6 & 16 & 6 & 51 \\
\hline Percent of row & 45.7 & 9.3 & 33.6 & 11.4 & 100 \\
\hline \multicolumn{6}{|c|}{ Working, caregiving } \\
\hline Number & 15 & 46 & 7 & 19 & 87 \\
\hline Percent of row & 15.2 & 56.9 & 7.2 & 20.7 & 100 \\
\hline Total & 946 & 1,291 & 163 & 180 & \\
\hline
\end{tabular}

Note: Percents are weighted numbers; counts are unweighted.

Table 9.5

Degree of labor force attachment, 1992 to 1998

\begin{tabular}{lrrrr}
\hline & \multicolumn{4}{c}{1998 Status } \\
\cline { 2 - 5 } & $\begin{array}{c}\text { Not } \\
\text { working/not } \\
\text { caregiving }\end{array}$ & $\begin{array}{c}\text { Working } \\
\text { only }\end{array}$ & $\begin{array}{c}\text { Caregiving } \\
\text { only }\end{array}$ & $\begin{array}{r}\text { Working/ } \\
\text { caregiving }\end{array}$ \\
\hline N92 Status & & & & \\
Not working/not caregiving & 0.0 & 0.0 & 0.0 & 0.0 \\
Mean hours worked $t$ & 2,261 & 5,111 & 1,206 & 5,485 \\
Mean earnings in previous year & 0.0 & 31.5 & 0.0 & 22.1 \\
Mean change in hours & 0.0 & 0.0 & 691 & 317 \\
Mean hours of care $t+1$ & & & & \\
Working only & 37.3 & 39.4 & 35.4 & 41.6 \\
Mean hours worked $t$ & 20,032 & 21,745 & 17,887 & 24,666 \\
Mean earnings in previous year & -37.3 & -1.2 & -35.4 & -1.9 \\
Mean change in hours & 0.0 & 0.0 & 932 & 544 \\
Mean hours of care $t+1$ & & & & \\
Caregiving only & 0.0 & 0.0 & 0.0 & 0.0 \\
Mean hours worked $t$ & 2,138 & 6,684 & 1,212 & 5,819 \\
Mean earnings in previous year & 0.0 & 32.3 & 0.0 & 20.1 \\
Mean change in hours & 0.0 & 0.0 & 1,087 & 258 \\
Mean hours of care $t+1$ & & & & \\
Working, caregiving & 39.8 & 44.0 & 39.9 & 51,3 \\
Mean hours worked $t$ & 16,462 & 18,067 & 21,152 & 18,006 \\
Mean earnings in previous year & -39.9 & -6.3 & -39.9 & -4.7 \\
Mean change in hours & 0.0 & 0.0 & 1,623 & 555 \\
Mean hours of care $t+1$ & & & & \\
\hline
\end{tabular}


As was the case in the year-to-year comparisons, with this longdifference comparison, there are surprisingly similar probabilities of transiting to caregiving for women who are working only and women who are not working/not caregiving. Less than 13 percent $(9.8+2.8)$ of those not working and not caregiving in 1992 were caregiving in 1998, and 11.6 percent $(3.7+7.9)$ of those who were just working initially were providing care in the later year. Similarly, there are numerous transitions out of caregiving. Fewer than half of those who were caregiving only in 1992 were caregiving (either with or without work) in 1998. Among those who were working and caregiving in 1992, only 20.7 percent were still in this category in 1998, and just 28 percent were providing care at all. Again though, these results do not show whether the respondent has stopped providing care because the parent or parent-in-law has had an improvement in functioning, has found an alternative source of care, or has died.

Comparing initial hours, earnings, and change in hours worked for those working only in 1992 (table 9.5) there are again only very small differences across outcomes. The women in the 1998 working only group and the working and caregiving groups appear to have nearly equal ties to the labor force. If anything, those who are eventually working and caregiving may have had stronger ties. For those who started out as working only, this group averaged 41.6 hours in 1992 compared to an average of 39.4 hours for those who remain working only. Similarly, the 1998 working and caregiving group had higher earnings, $\$ 24,666$ compared to $\$ 21,745$. Neither group experiences much in the way of a decline in hours. Those who were working only in 1992 and not working in 1998 averaged 37 and 35 hours per week in 1992 if they did not and did subsequently provide care. Consistent with a strong income effect, these women who leave the labor force had lower earnings than those who remain, and those who leave and provide care have the lowest. Perhaps surprisingly, those who are initially working and caregiving (bottom set of results) have earnings and hours that are similar to those who were initially working only although their slightly greater number of hours, and lower earnings may indicate a lower hourly wage.

\subsubsection{Multivariate Analyses of Caregiving and Work}

Certainly these women likely differ across categories in measures other than caregiving and labcr market behavior, and the observed patterns may reflect these underlying differences as well. The age distribution of caregivers may differ from that of noncaregivers, and their levels of schooling, marital status, number of siblings, and so forth may differ. In particular, women who are in better health may be better able to handle the rigors of working and the rigors of caregiving. I therefore turn to regression analysis to control for these other factors while examining the link between market behavior and caregiving. 
I examine the work and caregiving decision in 1998 using a bivariate probit model. In this cross-sectional analysis, I restrict my sample to those individuals who have a living parent or parent-in-law in 1998 and who were not providing care at the start of the survey, so this is a sample of "new" caregivers. It is this group who is of perhaps of most interest to policymakers - women who may be forced prematurely from the labor market in order to provide assistance to an elderly parent. The final sample for the multivariate analyses consists of 2,015 women with a living parent or parent-in-law in 1998.

The results of the estimation are reported in table 9.6. The first pair of columns presents the coefficient estimates and standard errors for the

\begin{tabular}{|c|c|c|}
\hline \multirow[b]{2}{*}{ Variable } & \multicolumn{2}{|c|}{ Specification 1} \\
\hline & Working & Caring \\
\hline \multicolumn{3}{|l|}{ Age } \\
\hline \multicolumn{3}{|l|}{ Less than 55 (omitted) } \\
\hline $55-61$ & $-.26(.07)$ & $.01(.10)$ \\
\hline $62-64$ & $-.85(.16)$ & $-.02(.14)$ \\
\hline 65 and over & $-1.38(.13)$ & $-.05(.16)$ \\
\hline \multicolumn{3}{|l|}{ Health status } \\
\hline \multicolumn{3}{|l|}{ Excellent (omitted) } \\
\hline Very good & $.90(.09)$ & $-.02(.12)$ \\
\hline Good & $-.00(.09)$ & $.09(.12)$ \\
\hline Fair & $-.59(.10)$ & $.11(.14)$ \\
\hline Poor & $-1.50(.16)$ & $-.11(.19)$ \\
\hline Married & $-.28(.09)$ & $-.23(.11)$ \\
\hline Net worth $(\$ 1,000 \mathrm{~s})$ & $-.22(.06)$ & $-.02(.06)$ \\
\hline \multicolumn{3}{|l|}{ Schooling } \\
\hline Less than high school & $-.13(.08)$ & $-.04(.11)$ \\
\hline \multicolumn{3}{|l|}{ High school (omitted) } \\
\hline Some college & $-.08(.08)$ & $.04(.19)$ \\
\hline College & $.19(.09)$ & $.09(.33)$ \\
\hline White & $-.07(.08)$ & $-.03(.12)$ \\
\hline \multicolumn{3}{|l|}{ Family characteristics } \\
\hline Parent needs care & $-.05(.07)$ & $1.09(.08)$ \\
\hline Number of sisters & $-.005(.02)$ & $-.02(.03)$ \\
\hline Number of brothers & $.007(.02)$ & $.07(.03)$ \\
\hline Number of sisters-in-law & $-.000(.03)$ & $-.01(.04)$ \\
\hline Number of brothers-in-law & $-.007(.03)$ & $-.05(.04)$ \\
\hline Intercept & $1.46(.47)$ & $-2.71(.64)$ \\
\hline Cross-equation correlation & \multicolumn{2}{|c|}{$-0.027(0.049)$} \\
\hline Number of observations & \multicolumn{2}{|c|}{2,271} \\
\hline Log likelihood & \multicolumn{2}{|c|}{$-2,028.18$} \\
\hline
\end{tabular}

Note: Also included are spousal earnings, asset income, other income, number of own children, number of children living at home, marital status, and Hispanic. 
probability of working in 1998 , and the second shows the probability of providing care. The variables tend to operate in the expected directions. There is a strong negative and monotonic relationship between both age and poor health and working. There do not, however, appear to be significant differences by age in the probability of providing care. Unsurprisingly, being married significantly reduces the probability of employment for this sample of women. Consistent with past studies that have found that unmarried daughters were the most likely caregivers, married women in this sample are less likely to provide care. The standard wealth effect is also observed in that the probability of work is significantly negatively related to assets, but there is no apparent relationship between assets and caregiving. One might have imagined that there would be a negative relationship in this case in that those with more resources could purchase formal care for elderly parents rather than provide their own time.

As expected from studies of women's labor force participation, a college education significantly increases the employment probability. However, it does not have an effect on caregiving. If schooling level is viewed as a proxy for the opportunity cost of a respondent's time, it is surprising that it does not have a more powerful negative effect on caregiving. Race is strongly related to caregiving, with Whites significantly more likely than non-Whites to provide care.

Of particular interest is the variable indicating that a parent or parentin-law needs care. This variable summarizes responses to questions asking if a particular parent "needs help with basic personal needs like dressing, eating, or bathing." The variable is equal to one if at least one parent needs care.$^{20}$ If women were leaving the labor market to provide care, then having a needy parent or parent-in-law should be negatively related to employment. Here, however, although the estimated effect is negative, it is not statistically different from zero, and, in fact, the point estimate is smaller than the standard error. This result is consistent with the finding of tables $9.2,9.3,9.4$, and 9.5. There is no effect of caregiving on employment probabilities. In contrast, having a parent or parent-in-law who needs care has a large effect on the probability of providing care.

Past research has demonstrated that women are more likely to provide care than men. It is therefore instructive to ask whether the caregiving decisions of women are affected by the sex of their siblings. As shown in table 9.6, the sex distribution of siblings does not affect work behavior, but the number of brothers does have a positive and significant effect on caregiving. Women with more brothers are more likely to provide care, but additional sisters have no effect.

20. I experimented with separate indicators for the need of a mother, father, mother-in-law, and father-in-law, but the individual categories are relatively unlikely. For example, 4 percent of the sample reports having a father who needs care, and just 3 percent have a needy fatherin-law. 
The bivariate probit model allows for a correlation between the error terms for the two equations. An examination of this correlation provides a test for whether unobserved characteristics of the individual that affect work also affect caregiving. For instance, there may be "energetic people" who are more likely to do both, or, conversely, some individuals might specialize in market activity while others specialize in home production. The correlation across regressions in this specification is negative, suggesting an explanation along the lines of the latter story, but the relationship is not significantly different from zero.

\subsection{Conclusion}

This study has provided a first look at transitions to caregiving. Results from simple transition matrices indicate that eventual caregivers were not less likely to be employed in prior periods than noncaregivers and did not work fewer hours. They also did not appear to have substantially lower earnings. These results are consistent with anecdotal evidence that women appear to cut back on leisure rather than work when providing care to an elderly parent. As Cantor (1983) notes, "the most severe impact [of caregiving] was registered in areas such as free time for oneself and opportunities to socialize with friends, take vacations, have leisure time pursuits, and run one's own house" (600).

The results of a multivariate analysis similarly fail to support a strong relationship between labor market ties and caregiving later in life. Having a parent who needs care does not affect employment behavior, and lagged labor force participation does not affect current caregiving.

Despite these conclusions, many questions remain. Of interest is the extent to which women are able to remain in the labor force because of accommodations made by employers. Stone and Short (1990) found little effect of caregiving on employment in general but significant effects on the likelihood that accommodations were required on the job. If accommodations are important, then the effect of caregiving on labor market behavior would be most severely felt by those with little flexibility on the job. If this flexibility is positively correlated with measures of socioeconomic status, such as schooling and income, then it may be the poor who are most likely harmed. Some of the evidence presented here suggests that caregivers may have lower wage rates, perhaps indicative of less investment on the job or of a cost of any needed accommodations.

Finally, the lack of an employment response does not mean all is well. Numerous studies have reported a high level of stress among caregivers. The task of providing care to an elderly parent may therefore have large negative effects on caregivers in terms of emotional well-being. If psychological stress is associated with deteriorations in health and shorter life expectancy, this could also be costly in economic terms. 


\section{References}

Arno, Peter, Carol Levine, and Margaret Memmott. 1999. The economic value of informal caregiving. Health Affairs 18 (2): 182-88.

Boaz, Rachel, and Charlotte Muller. 1992. Paid work and unpaid help by caregivers of the disabled and frail elders. Medical Care 30 (2): 149-58.

Brody, Elaine, and Claire Schoonover. 1986. Patterns of parent care when adult daughters work and when they do not. The Gerontologist 21:371-81.

Brown, Jeffrey, and Amy Finkelstein. 2003. Why is the market for private long-term care insurance so small? The role of pricing and Medicaid crowd-out. University of Illinois. Mimeograph.

Cantor, Marjorie. 1983. Strain among caregivers: A study of experience in the United States. The Gerontologist 23 (6): 597-604.

Centers for Medicare and Medicaid Services. n.d.a. Medicare coverage of skilled nursing facility care. Washington, DC: Centers for Medicare and Medicaid Services.

- n.d.b. Medicare and home health care. Washington, DC: Centers for Medicare and Medicaid Services.

Commonwealth Fund. 1999. FACT SHEET: Informal caregiving, fact sheet from The Commonwealth Fund 1998 Survey of Women's Health. New York: Commonwealth Fund.

Coward, Raymond, and Jeffrey Dwyer. 1990. The association of gender, sibling network composition, and patterns of parent care by adult children. Research on Aging 12:158-81.

Department of Health and Human Services (DHHS). 1998. Informal caregiving compassion in action. Washington, DC: DHHS, Office of the Assistant Secretary for Planning and Evaluation.

Dwyer, Jeffrey, and Raymond Coward. 1991. A multivariate comparison of the involvement of adult sons versus daughters in the care of impaired parents. Journal of Gerontology: Social Sciences 46:S259-S269.

Ettner, Susan. 1995. The impact of "parent care" on female labor supply decisions. Demography 32 (1): 63-80.

-. 1996. The opportunity costs of elder care. The Journal of Human Resources 31 (1): 189-205.

Finkelstein, Amy, and Kathleen McGarry. Forthcoming. Multiple dimensions of private information: Evidence from the Long-term Care Insurance Market. American Economic Review.

Hurd, Michael, and Kathleen McGarry. 1993. The relationship between job characteristics and retirement. NBER Working Paper no. 4558. Cambridge, MA: National Bureau of Economic Research, December.

Juster, Thomas, and Richard Suzman. 1995. An overview of the Health and Retirement Study. The Journal of Human Resources 30 (Supplement): S7-S56.

McGarry, Kathleen. 1998. Caring for the elderly: The role of adult children. In Inquiries in the economics of aging, ed. David A. Wise, 133-63. Chicago: University of Chicago Press.

2002. Public policy and the U.S. health insurance market: Direct and indirect provision of insurance. National Tax Journal 55 (4): 789-827.

Metropolitan Life Insurance Company. 2002. MetLife market survey on nursing home and home care costs. Westport, CT: MetLife Mature Market Institute.

Stern, Steven. 1995. Estimating family long-term care decisions in the presence of endogenous child characteristics. The Journal of Human Resources 30 (3): $551-80$. 
Stone, Robyn, Gail Cafferata, and Judith Sangl. 1987. Caregivers of the frail elderly: A national profile. The Gerontologist 27 (5): 616-26.

Stone, Robyn, and Pamela Farley Short. 1990. The competing demands of employment and informal caregiving to disabled elders. Medical Care 28 (6): 513-26.

Walker, David. 2002. Long-term care: aging baby boom generation will increase demand and burden on federal and state budgets. United States General Accounting Office, Testimony before the Special Committee on Aging, U.S. Senate, March 21, 2002.

Wolf, Douglas, Vicki Freedman, and Beth Soldo. 1997. The division of family labor: Care for elderly parents. Journals of Gerontology: Social Sciences 52:102-09.

Wolf, Douglas, and Beth Soldo. 1994. Married women's allocation of time to employment and parental care. The Journal of Human Resources 29 (4): 1259-76. 